\title{
Pregnancy outcome and clinical status of gilts following experimental infection by H1N2, H3N2 and H1N1pdm09 influenza A viruses during the last month of gestation
}

\author{
Krzysztof Kwit $^{1}$ - Małgorzata Pomorska-Mól ${ }^{1} \cdot$ Iwona Markowska-Daniel $^{1}$
}

Received: 26 April 2015/Accepted: 27 June 2015/Published online: 11 July 2015

(C) The Author(s) 2015. This article is published with open access at Springerlink.com

\begin{abstract}
The present study was planned to study the effect of various subtypes of swine influenza virus (SIV) circulating among pigs (H1N2, H3N2 and emerging pandemic strain of H1N1 influenza A virus (H1N1pdm09) on the course of pregnancy in naïve gilts experimentally infected during the last month of pregnancy. In addition, the clinical course of infection, distribution of viruses in various tissues (blood, placenta, fetal lung), and selected immunological, reproductive and productive parameters were also investigated. All SIV-inoculated gilts became infected. No abortions, stillbirths, intrauterine deaths or mummified fetuses were observed. No clinical signs of influenza virus infection or other disorders were observed in piglets born from infected and control gilts. There was a significant decrease in the number and frequency of lymphocytes in gilts inoculated with all influenza viruses. In general, the concentrations of IL-6, IL-10 and TNF- $\alpha$ were significantly higher in SIV-inoculated gilts as than in control animals, while IL- 4 and IFN- $\gamma$ were not detected in plasma at any time post-inoculation in SIV- or mockinoculated gilts. No evidence for transplacental transmission of SIV was found. Viremia was also not observed in any of the infected females. On the basis of recent results, we hypothesize that pregnancy failure observed during SIV infection under field conditions is probably related to high fever and pro-inflammatory cytokines rather than a direct effect of the virus on the placenta, embryo or fetus.
\end{abstract}

Małgorzata Pomorska-Mól mpomorska@piwet.pulawy.pl

1 Department of Swine Diseases, National Veterinary Research Institute, Partyzantów 57, 24-100 Pulawy, Poland

\section{Introduction}

There are several infectious agents that have the potential to cause reproductive failure in pigs [1]. Infections of pregnant females with some of them often pass unnoticed; however, the pathogen may still pass the placenta and infect the embryo or/and fetus [1]. In contrast, other pathogens cause clear clinical signs that result (directly or indirectly) in abortions, fetal deaths or other reproduction disorders [1]. Among the second group of pathogens, swine influenza virus (SIV) is often mentioned [2,3].

Swine influenza (SI) is characterized by high morbidity and low mortality. The main clinical signs are fever, coughing, dyspnea, inappetence and weight loss. However, abortion, stillbirth, fetal deaths and other reproductive disorders can be also associated with epidemics of SI [3-5]. Abortions in influenza A virus (IAV)-infected humans as well as animals, including pigs, seem to be a result of high fever and a "cytokine storm" associated with acute infection, but transplacental transmission of the virus has been also reported [5-10]. Influenza virus has also been isolated from amnion and chorion tissues in guinea pigs [11] and amniotic fluid in ferrets [12]. To date, there is insufficient data to conclude that IAV has a specific and direct association with the occurrence of reproductive problems.

Swine influenza virus has been isolated from farms where reproductive disorders have been reported, but its effect on swine reproduction is not completely understood [10, 13]. In the study of Madec et al. [5], only $23 \%$ of sows infected with SIV in their first week of pregnancy completed gestation and farrowed; in $25 \%$ of sows that were one month into gestation, total embryonic resorption occurred; and in the $5.5 \%$ of sows that were more than 45 days into gestation, an abortion 
occurred [5]. Swine influenza virus was detected in an aborted fetus [5]. The results obtained by Young and Underdahl [14] revealed that pigs born to sows that had been inoculated with SIV had higher mortality rates and lower weaning weights than those from control sows [14]. Sporadic abortions late in pregnancy and increased stillbirths have also been reported during SI outbreaks $[2,3,10,15,16]$.

To date, the mechanisms responsible for the reproductive disorders during influenza virus infection have not been finally clarified. Although influenza virus infections in humans are known to increase the risk of adverse pregnancy outcomes, the effects of maternal influenza virus infection on the fetus are not well understood. The influence of SIV infection in pigs on the course of pregnancy and on the fetus is also poorly understood.

In previous studies, we have evaluated the effect of H1N2 SIV infection in gilts during the first and the second month of pregnancy $[23,24]$. The results of these studies indicated that infection of pregnant gilts with swine H1N2 IAV in the earlier stages of pregnancy did not cause abortion or reproduction failure, and no evidence for transplacental transmission of H1N2 SIV was noted. However, due to the diversity of IAV it cannot be excluded that other subtypes of IAV could be associated with reproduction failure in pigs. Moreover, the stage of pregnancy during SIV infection might be an important factor influencing the risk of reproduction disorders.

For these reasons, we have decided to evaluate the effect of infection with various subtypes of SIV circulating among pigs $(\mathrm{H} 1 \mathrm{~N} 2, \mathrm{H} 3 \mathrm{~N} 2$ and the emerging pandemic strain of H1N1 SIV (H1N1pdm09) on the course of pregnancy in naïve gilts experimentally infected during the last month of pregnancy. In addition, the clinical course of infection and selected immunological, reproductive and productive parameters were also investigated.

\section{Materials and methods}

\section{Animals}

A total of 36 gilts (PIC, Camborough 46) at the age of 8 months and their litters were used. The gilts were obtained from a farm with high health status. All gilts were SIV and antibody (H1N1, H1N2, H3N2, H1N1pdm09) negative. They were also seronegative for porcine reproductive and respiratory syndrome virus (PRRSV), pseudorabies virus (PRV) and leptospira. Gilts were divided into 8 groups (Table 1).

Gilts were inseminated, and the pregnancy was confirmed by ultrasonography at 24 and 58 days post-insemination. The prophylactic program during gestation consisted of vaccination against parvovirus infection, erysipelas and colibacillosis. During the experiment, gilts were housed in isolated units, one for the each group of gilts. The condition of piglets was monitored until weaning (4 weeks old).

Animal use and handling protocols were approved by the local ethics commission (University of Life Sciences in Lublin, Poland; Permit Number: 72/2010). All efforts were made to minimize animal suffering.

\section{Preparation of inoculum}

Viruses and doses used for experimental infection are listed in Table 1. The concentration of SIV was determined in Madin-Darby canine kidney (MDCK) cells. Virus titers were calculated by the Reed-Muench method.

\section{Experimental design}

Ninety days post-insemination (day 0 of the study), gilts were inoculated intranasally (IN) or intratracheally (IT) with SIV. The appropriate dose of the particular virus (Table 1) in $10 \mathrm{ml}$ of phosphate-buffered saline (PBS) was given IN ( $5 \mathrm{ml}$ to each nostril) or IT. Six mock-inoculated females served as controls.
Table 1 Study design - viruses used for inoculation, route and dose of inoculation

\begin{tabular}{lllll}
\hline & $\begin{array}{l}\text { Number } \\
\text { of gilts }\end{array}$ & $\begin{array}{l}\text { Route of } \\
\text { inoculation }\end{array}$ & Virus used for inoculation & Dose \\
\hline Group 1 & 5 & IN & H1N2 (A/swine/Granstedt/IDT3475/2004) & $7 \times 10^{7.5} \mathrm{TCID}_{50}$ \\
Group 2 & 5 & IT & H1N2 (A/swine/Granstedt/IDT3475/2004) & $7 \times 10^{7.5} \mathrm{TCID}_{50}$ \\
Group 3 & 5 & IN & H3N2 (A/swine/Gent/172/08) & $7 \times 10^{7.5} \mathrm{TCID}_{50}$ \\
Group 4 & 5 & IT & H3N2 (A/swine/Gent/172/08) & $7 \times 10^{7.5} \mathrm{TCID}_{50}$ \\
Group 5 & 5 & IN & H1N1pdm09 (A/California/04/09) & $8 \times 10^{7.0} \mathrm{TCID}_{50}$ \\
Group 6 & 5 & IT & H1N1pdm09 (A/California/04/09) & $8 \times 10^{7.0} \mathrm{TCID}_{50}$ \\
Group 7 & 3 & IN & Control & na \\
Group 8 & 3 & IT & Control & na \\
\hline
\end{tabular}

IN, intranasal inoculation; IT, intratracheal inoculation 


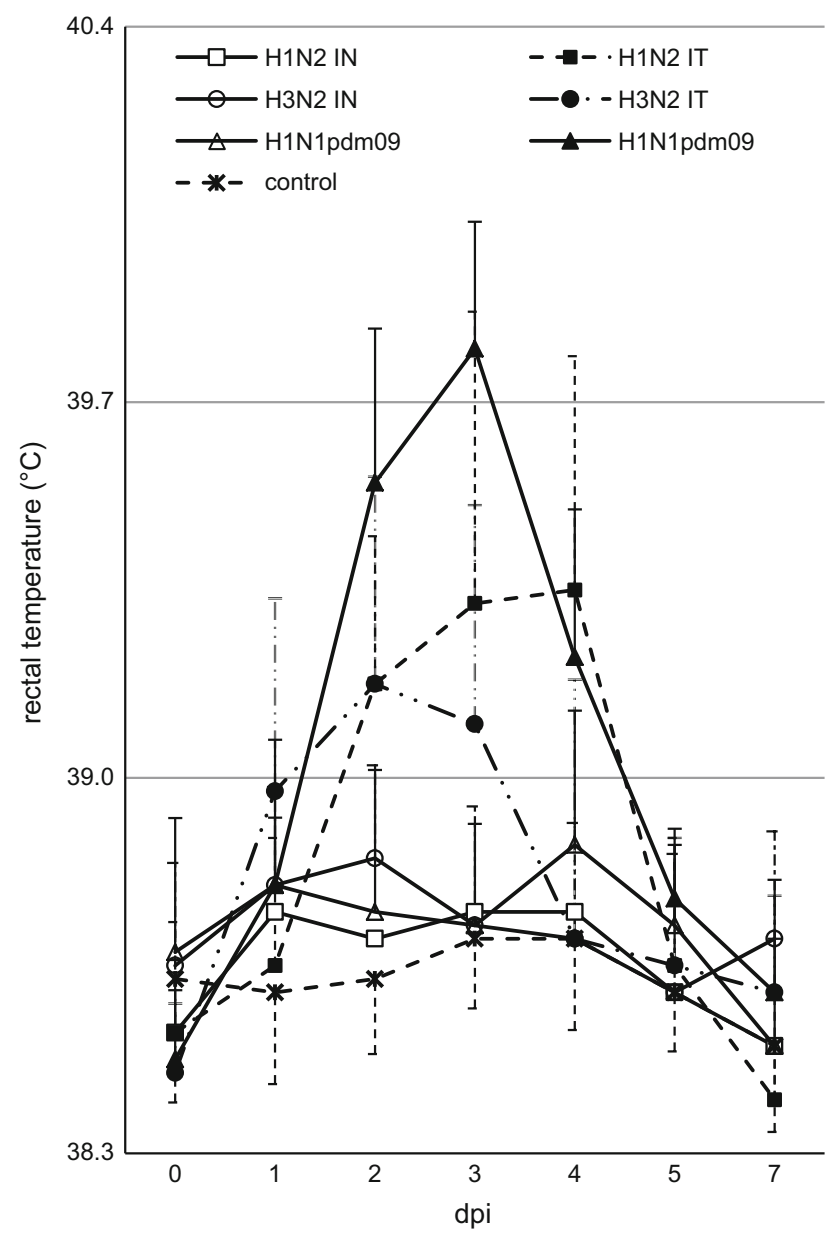

Fig. 1 The mean $( \pm \mathrm{SD})$ temperature in gilts infected intranasally (IN) or intratracheally (IT) with H1N2, H3N2 or H1N1pdm09 swine influenza viruses and in control gilts

Temperatures and clinical signs were recorded from day 0 to day 7 post-inoculation (dpi); however, the health status of gilts was monitored until the end of pregnancy. The gilts were observed and scored for clinical signs according to a scheme described previously $[17,23]$. Fever was recorded when the rectal temperature was equal to or higher than $39.7{ }^{\circ} \mathrm{C}$.

Blood samples from gilts were taken on days $-7,0$ (inoculation), 4, 7, 14, 21 and 28 dpi. Blood samples from piglets were collected before they consumed colostrum (5 piglets per litter). Nasal swabs were taken from gilts at 0,1 , $2,3,4,5$ and $7 \mathrm{dpi}$, and from the piglets immediately after birth. All placentas were collected aseptically at delivery and frozen at $-80{ }^{\circ} \mathrm{C}$ until their use for viral RNA extraction.

Two of the weakest piglets from the litter were sacrificed and necropsied, with special emphasis on the respiratory tract. Sodium pentobarbital was used for euthanasia. Lung, trachea and nasal mucosa were collected aseptically and frozen at $-80{ }^{\circ} \mathrm{C}$ until their use for viral RNA extraction.

\section{Reproductive and production parameters}

The gestation length, and litter characteristics (number of piglets born alive, stillborn and mummified piglets, individual birth weights of piglets [kg], litter birth weight $[\mathrm{kg}]$, and number of piglets dying during the first week of life) were determined.

\section{Detection of SIV RNA in nasal swabs, and blood and tissue samples}

For detection of SIV RNA in the blood (gilts, piglets), nasal swabs (gilts, piglets), placentas, and tissues collected during necropsy of piglets, a real-time RT-PCR test was used according to a protocol described previously [18, 23]. Realtime RT-PCR results are given as ++ (positive results, $\mathrm{Ct}$ [cycle threshold] values $<30$ ), + (weak positive results, $\mathrm{Ct}$ values 30-35), or - (negative results, $\mathrm{Ct}$ values $>35$ ).

\section{Hematological parameters}

Blood samples were tested using a hematologic analyzer (Abacus Junior Vet 5, Diatron, Hungary) to determine the numbers of white blood cells (WBC) as well as the numbers and percentage of lymphocytes (LYM) and granulocytes (GRA).

\section{Proliferative response of peripheral blood mononuclear cells (PBMCs)}

The proliferation assay was done at $0,4,7,14$ and $21 \mathrm{dpi}$ as described previously [18-20]. The cells were restimulated with $50 \mu \mathrm{l}$ of medium containing live viruses that were used for inoculation of gilts $\left(10^{6.8} \mathrm{TCID}_{50} / 50 \mu \mathrm{l}\right.$ of $\mathrm{H} 1 \mathrm{~N} 2$ or $10^{6.5} \mathrm{TCID}_{50} / 50 \mu \mathrm{l}$ of $\mathrm{H} 3 \mathrm{~N} 2$ or $10^{6.8} \mathrm{TCID}_{50} /$ $50 \mu \mathrm{l}$ of H1N1pdm09). In control tubes, the cells were mock-stimulated (unstimulated control) or stimulated with $5 \mu \mathrm{g} / \mathrm{ml}$ of concanavalin (Con-A) (viability control). All samples were analysed in triplicate. The cells were incubated for 72 hours at $37{ }^{\circ} \mathrm{C}$ in a $5 \% \mathrm{CO}_{2}$ atmosphere before they were pulsed with $0.5 \mu \mathrm{Ci}$ of $\left[{ }^{3} \mathrm{H}\right]$-thymidine (PerkinElmer, USA). After 18 hours of incubation, PBMCs were harvested, and the incorporated radioactivity was measured in an ultra-low-background liquid scintillation counter (Quantulus, PerkinElmer, USA). Proliferation was expressed as a stimulation index (SIx) calculated as follows: the number of counts per minute $(\mathrm{cpm})$ for SIVstimulated PBMCs divided by the number of $\mathrm{cpm}$ for the unstimulated control cells. 
Table 2 Reproductive and production parameters of gilts infected intranasally (IN) or intratracheally (IT) with H1N2 (A/swine/Granstedt/ IDT3475/2004), H3N2 (A/swine/Gent/172/08) and H1N1pdm09 (A/California/04/09) influenza A viruses and in control gilts (mean \pm SD)

\begin{tabular}{|c|c|c|c|c|c|c|c|}
\hline $\begin{array}{l}\text { Virus used for } \\
\text { inoculation }\end{array}$ & $\begin{array}{l}\text { Route of } \\
\text { inoculation }\end{array}$ & $\begin{array}{l}\text { Average } \\
\text { gestation length }\end{array}$ & $\begin{array}{l}\text { Average } \\
\text { pigs/litter }\end{array}$ & $\begin{array}{l}\text { Average pigs born } \\
\text { alive/litter }\end{array}$ & $\begin{array}{l}\text { First week } \\
\text { mortality/litter }\end{array}$ & $\begin{array}{l}\text { Average liter } \\
\text { weight }(\mathrm{kg})\end{array}$ & $\begin{array}{l}\text { Average birth } \\
\text { weight }(\mathrm{kg})\end{array}$ \\
\hline \multirow[t]{2}{*}{$\mathrm{H} 1 \mathrm{~N} 2$} & IN & $114.8 \pm 0.84$ & $12.33 \pm 0.58$ & $12.33 \pm 0.58$ & $0.80 \pm 0.89$ & $17.29 \pm 1.98$ & $1.42 \pm 0.02$ \\
\hline & IT & $114.8 \pm 0.44$ & $11.66 \pm 1.15$ & $11.66 \pm 1.15$ & $0.40 \pm 0.54$ & $17.07 \pm 1.85$ & $1.47 \pm 0.03$ \\
\hline \multirow[t]{2}{*}{$\mathrm{H} 3 \mathrm{~N} 2$} & IN & $115.2 \pm 0.84$ & $12.66 \pm 1.53$ & $12.66 \pm 1.53$ & $1.33 \pm 0.58$ & $17.30 \pm 1.56$ & $1.37 \pm 0.07$ \\
\hline & IT & $115.2 \pm 0.44$ & $12.00 \pm 1.00$ & $12.00 \pm 1.00$ & $1.00 \pm 1.00$ & $17.22 \pm 1.07$ & $1.40 \pm 0.02$ \\
\hline \multirow[t]{2}{*}{ H1N1pdm09 } & IN & $115.6 \pm 0.54$ & $13.00 \pm 1.00$ & $13.00 \pm 1.00$ & $0.66 \pm 0.58$ & $17.85 \pm 0.61$ & $1.38 \pm 0.08$ \\
\hline & IT & $115.2 \pm 0.58$ & $13.33 \pm 0.58$ & $13.33 \pm 0.58$ & $1.00 \pm 1.00$ & $17.69 \pm 1.00$ & $1.37 \pm 0.04$ \\
\hline Control & IN and IT & $115.0 \pm 0.76$ & $12.55 \pm 1.33$ & $12.55 \pm 1.33$ & $0.78 \pm 0.98$ & $17.41 \pm 1.23$ & $1.39 \pm 0.08$ \\
\hline
\end{tabular}

Fig. 2 The concentration of white blood cells (WBC), lymphocytes (LYM) and granulocytes (GRA) in gilts inoculated intranasally (IN) or intratracheally (IT) with H1N2, H3N2 or H1N1pdm09 swine influenza viruses and in control gilts. *, significant difference compared to the day 0 level ( $\mathrm{p}<$ 0.05 )
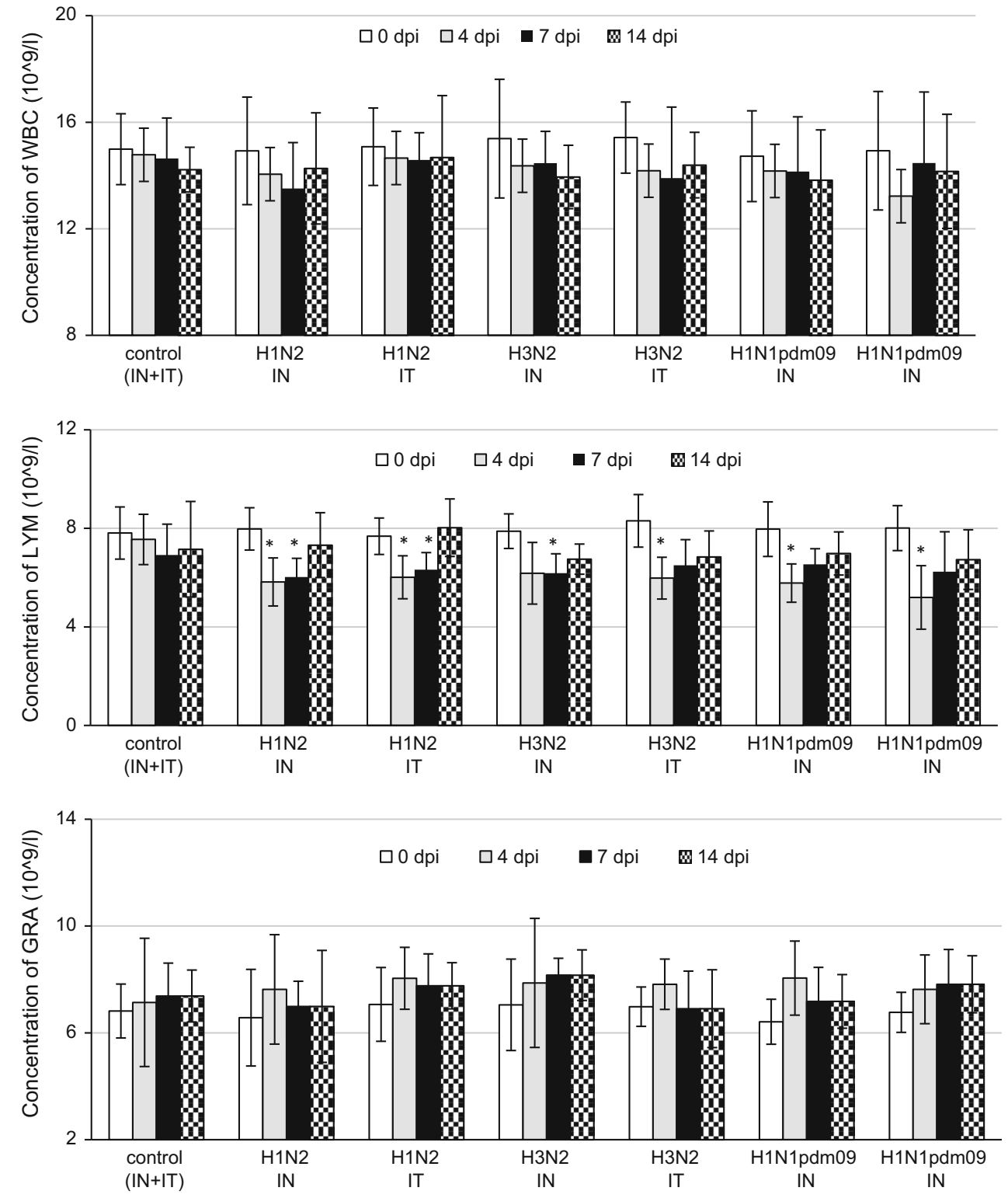


\section{Humoral immune response}

Antibodies against SIVs were measured using a haemagglutination inhibition (HI) assay according to the standard procedure [21], using of the following strains: H1N2 (A/ swine/Granstedt/IDT3475/2004), H3N2 (A/swine/Gent/ 172/08), and H1N1pdm09 (A/California/04/09). A sample was considered positive when its titre was $\geq 20$.

\section{Assays of cytokines in plasma}

The concentrations of IL-4, IL-6, IL-10, IFN- $\gamma$, and TNF- $\alpha$ in plasma samples were determined using ELISA kits (Invitrogen Corporation, USA; Abcam, UK) according to the manufacturers' protocols. Concentrations of cytokines were calculated from calibration curves generated using FindGraph software.

\section{Assays of acute-phase proteins (APP) in serum}

For determination of C-reactive protein (CRP) and haptoglobin (Hp), ELISA assays were used according to the manufacturers' instructions (Pig C-reactive protein ELISA and Pig haptoglobin ELISA from Life Diagnostics, Inc., USA). The quantity of APP was calculated based on a standard curve for each protein, using FindGraph software.

\section{Statistical analysis}

Kruskal-Wallis tests with post hoc multiple comparisons for comparison of all pairs and Friedman test were used for comparison of means (STATISTICA 8.0; StatSoft). For all analyses, $P<0.05$ was considered significant.

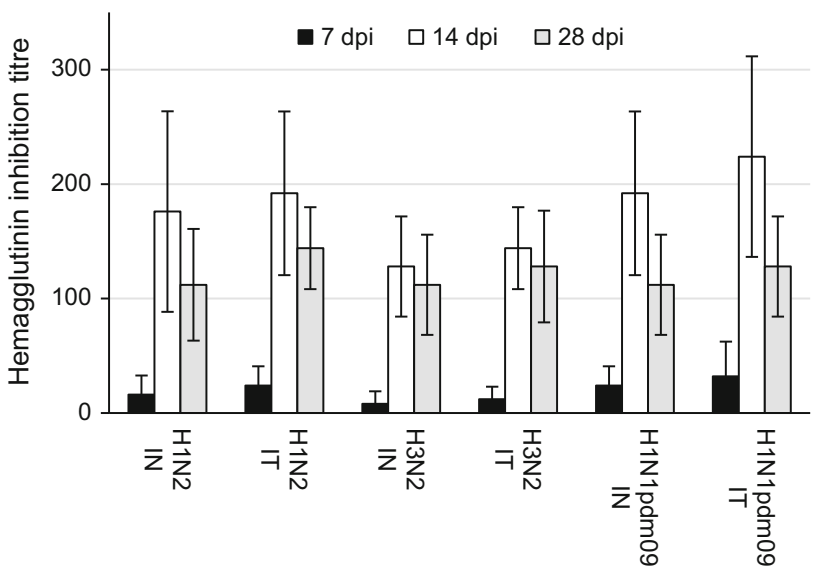

Fig. 4 Hemagglutinin inhibition (HI) titre in gilts inoculated intranasally (IN) or intratracheally (IT) with H1N2, H3N2 or H1N1pdm09 swine influenza viruses and in control gilts
Fig. 3 The frequency of lymphocytes (LYM) and granulocytes (GRA) in the peripheral blood of gilts inoculated intranasally (IN) or intratracheally (IT) with H1N2, $\mathrm{H} 3 \mathrm{~N} 2$ or $\mathrm{H} 1 \mathrm{~N} 1 \mathrm{pdm} 09$ swine influenza viruses and in control gilts. *, significant difference compared to the day 0 level $(\mathrm{p}<$ $0.05)$
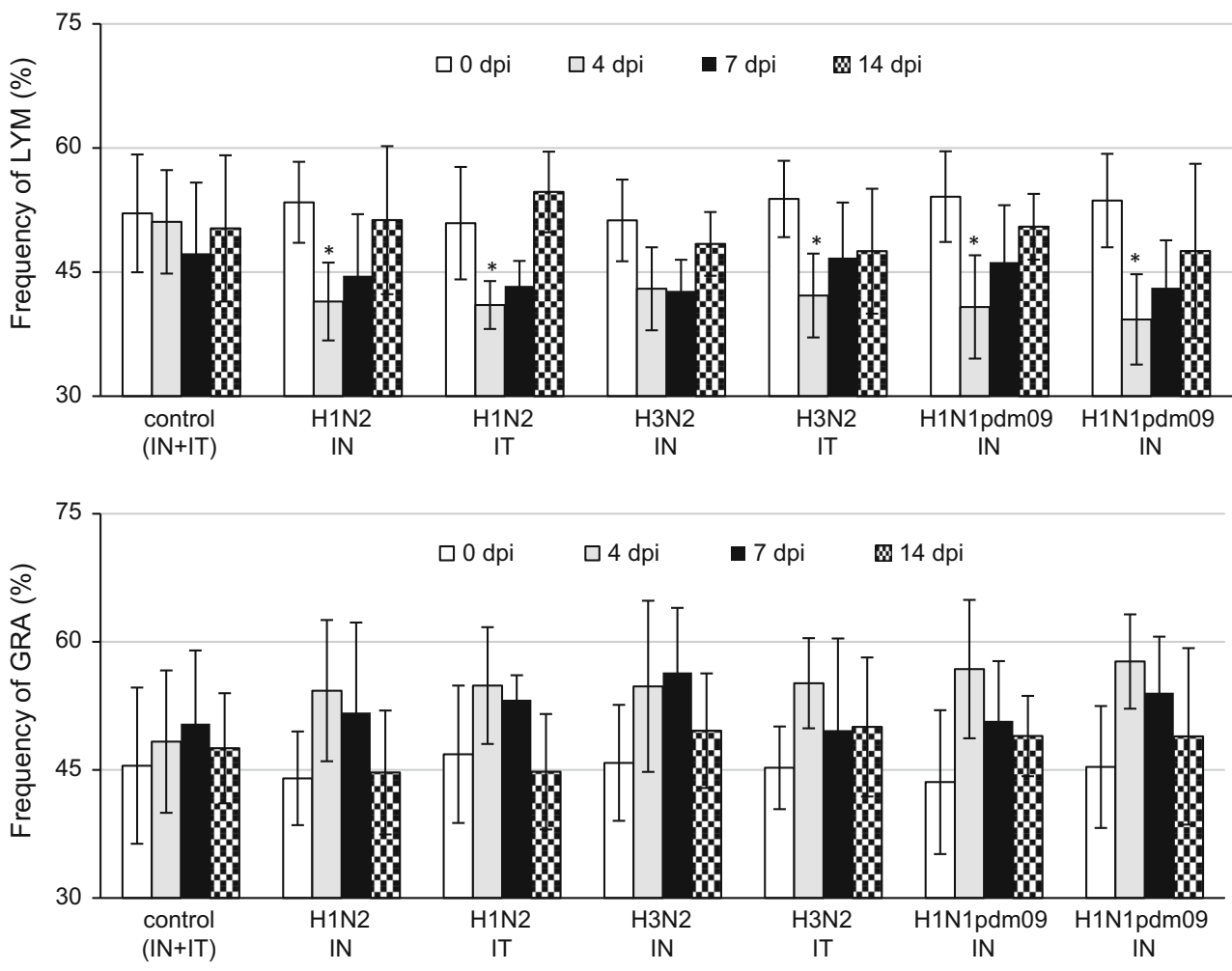


\section{Results}

\section{Clinical and pathological signs}

No obvious clinical signs were observed in the respiratory tract of pregnant gilts inoculated IN or IT with any of the viruses. Most of the SIV-inoculated gilts showed no systemic signs characteristic of influenza other than short-term fever in gilts inoculated IT (Fig. 1). Fever was defined when rectal temperature was $\geq 39.7{ }^{\circ} \mathrm{C}$.

The fever was recorded in 1 out of 5 females inoculated with H1N2 SIV, in 2 out of 5 pigs inoculated with H3N2 $\mathrm{SIV}$, and in 3 out of 5 pigs inoculated with H1N1pdm09 SIV. Similar results were obtained with regard to diminished activity. The mean clinical scores in control and INinoculated gilts were 0 . In gilts inoculated IT, the mean clinical scores were $0.4 \pm 0.89, \quad 0.8 \pm 1.09$ and $1.2 \pm 1.09$, respectively, for $\mathrm{H} 1 \mathrm{~N} 2, \mathrm{H} 3 \mathrm{~N} 2$ and H1N1pdm09 SIV. Postmortem examination of euthanized piglets did not reveal typical lesions deriving from SIV infection.

\section{Reproductive and production performance}

The gestation length in gilts from all groups was from 114 to 116 days. No abortions, stillbirths, intrauterine deaths or mummified fetuses were noted. No clinical signs of influenza virus infection or other disorders were observed in piglets born to infected or control gilts. The mean production and reproductive parameters for all experimental groups are presented in Table 2.

\section{Hematological parameters}

The number of WBCs in control and inoculated gilts was stable during the study (Fig. 2).
No significant differences between inoculated and control gilts were found $(p>0.05)$. There was a significant decrease in the number of lymphocytes in gilts inoculated with all SIV as compared to the day 0 level $(\mathrm{p}<0.05)$. This reduction was observed mainly at 4 dpi. In gilts inoculated with H1N2 SIV, the number of lymphocytes was significantly lower also at $7 \mathrm{dpi}(\mathrm{p}<0.05)$. A significant reduction in the percentage of lymphocytes as compared with the day 0 level was observed in gilts inoculated IN and IT with H1N2 SIV and H1N1pdm09 and inoculated IT with H3N2 SIV (Fig. 3). The percentage of granulocytes did not differ significantly between groups $(\mathrm{p}>0.05)$.

\section{Humoral response}

The HI titres are presented in Fig. 4. In control gilts, no specific antibodies against SIV (H1N1, H1N2, H3N2 and H1N1pdm09) were found.

Specific HI antibodies were detected in the serum of all inoculated gilts from 14 dpi. In some of the gilts $(3 / 5$ and $4 / 5$ inoculated IN or IT with H1N2 SIV, in $2 / 5$ and $3 / 5$ inoculated IN or IT with H3N2 SIV and in $4 / 5$ and $4 / 5$ inoculated IN or IT with H1N1pdm09), HI antibodies were detected also at $7 \mathrm{dpi}$. The highest $\mathrm{HI}$ titres were found at 14 dpi. No significant differences were found between gilts inoculated IN or IT $(p>0.05)$. No HI antibodies were detected in the serum of colostrum-deprived piglets or control gilts.

\section{Proliferative response of PBMCs}

On the basis of the SIx values in the control groups (mean value plus 3 standard deviations), SIx values higher than 2.26, 2.10 and 2.13, respectively, for H1N1, H3N2 and H1N1pdm09 virus were calculated, indicating antigen-
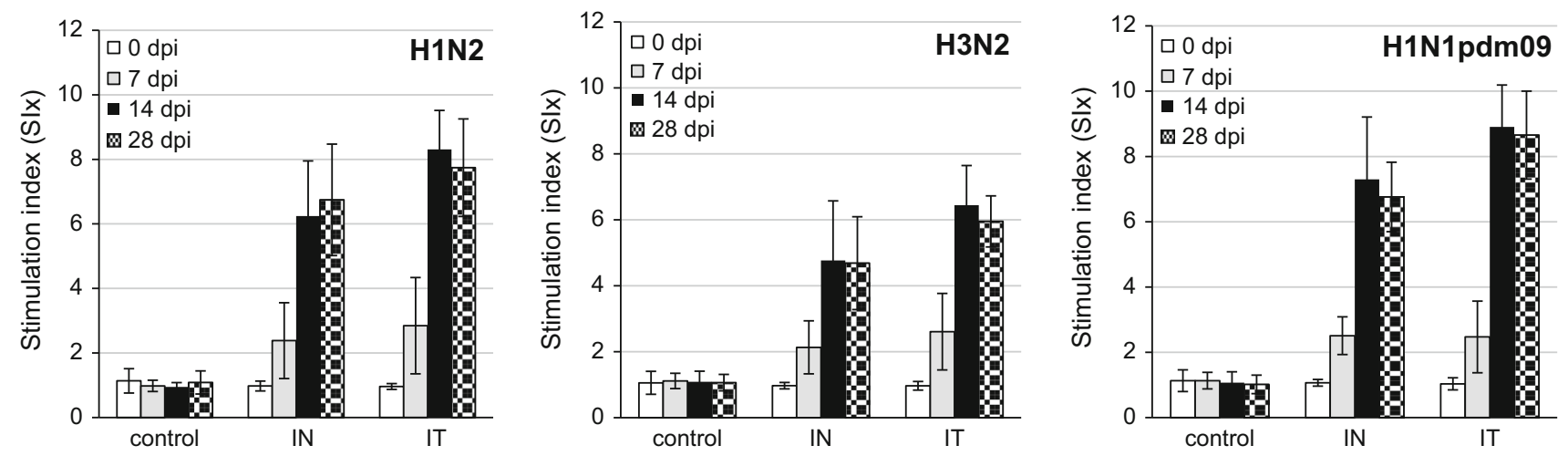

Fig. 5 The proliferative response of peripheral blood mononuclear cells isolated from gilts inoculated IN (intranasally) or IT (intratracheally) with $\mathrm{H} 1 \mathrm{~N} 2, \mathrm{H} 3 \mathrm{~N} 2$ or H1N1pdm09 swine influenza viruses and in control gilts. *, significant difference compared to the control group (p $<0.05$ ) 
specific proliferation. The mean SIx values are presented in Fig. 5.

From $14 \mathrm{dpi}$, antigen-specific proliferation was observed in all inoculated gilts. Some of the gilts responded earlier (at $7 \mathrm{dpi}$ ). There were no significant differences between females inoculated IN and those inoculated IT with the same virus at the same dpi $(p>0.05)$.

\section{Virus detection in clinical samples}

The genetic material of SIV was detected in nasal swabs taken from inoculated gilts between 2 and 5 dpi. Some gilts shed virus also at 1 or $7 \mathrm{dpi}$ (Table 3 ).

No SIV RNA was detected in nasal swabs taken from gilts before inoculation, control gilts, or newborn piglets. Also, no SIV RNA was detected in samples of lung and tracheas taken from piglets euthanized after delivery, or in placentas. There was no evidence of viremia in gilts and piglets.

\section{Systemic response of IL-4, IL-6, IL-10, IFN- $\gamma$ and TNF- $\alpha$}

Plasma concentrations of cytokines were evaluated at 0,4 , 7 and 14 dpi. In general, the concentration of IL-6, IL-10 and TNF- $\alpha$ were significantly higher in inoculated gilts than in control animals, while IL- 4 and IFN- $\gamma$ were not detected in plasma at any time post-inoculation in SIV- and mock-inoculated gilts. The time course of the mean concentrations of IL-6, IL-10 and TNF- $\alpha$ during the study period is shown in Fig. 6, 7 and 8, respectively.

The concentration of IL- 6 after IN inoculation was the highest at 4 dpi $(\mathrm{p}<0.05)$ (Fig. 6).

In gilts inoculated IN with H3N2 and H1N1pdm09 SIV, the level of IL-6 was significantly elevated at $7 \mathrm{dpi}$. In contrast, after IT inoculation a significantly higher concentration of IL-6 was observed in all infected gilts from 4 to 7 dpi. Moreover, in gilts inoculated with H1N1pdm09 SIV, and elevated level of IL- 6 was observed also at $14 \mathrm{dpi}$.

Similar responses were observed with regard to IL-10 (Fig. 7). After IN inoculation, a significant $(p<0.05)$ increase was observed in all inoculated groups from 4 to 7 dpi when compared to control gilts. After IT inoculation, significantly higher concentrations of IL-10 were observed at 4 and 7 dpi in gilts inoculated with H1N2 and H3N2 SIV and in gilts inoculated with H1N1pdm09 SIV from 4 to 14 dpi.

The concentration of TNF- $\alpha$ at 4 dpi was significantly higher only in gilts inoculated IN with $\mathrm{H} 3 \mathrm{~N} 2$ and H1N1pdm09 SIV (p < 0.05) (Fig. 8).

At $7 \mathrm{dpi}$, the concentration of TNF- $\alpha$ was significantly higher in all IN-inoculated gilts than in control females $(\mathrm{p}<0.05)$. After IT inoculation, a significant increase in
Table 3 Real-time RT-PCR results for clinical samples (nasal swabs) from gilts inoculated with intranasally (IN) or intratracheally (IT) with H1N2 (A/swine/Granstedt/IDT3475/2004), H3N2 (A/swine/ Gent/172/08) and H1N1pdm09 (A/California/04/09) influenza A viruses

\begin{tabular}{|c|c|c|c|c|c|c|c|c|c|}
\hline \multirow[t]{2}{*}{ Virus } & \multirow[t]{2}{*}{ Route } & \multirow{2}{*}{$\begin{array}{l}\text { Gilt } \\
\text { no. }\end{array}$} & \multicolumn{7}{|c|}{ Time postinfection (days) } \\
\hline & & & 0 & 1 & 2 & 3 & 4 & 5 & 7 \\
\hline \multirow[t]{10}{*}{$\mathrm{H} 1 \mathrm{~N} 2$} & \multirow[t]{5}{*}{ IN } & 1 & - & + & ++ & ++ & ++ & + & - \\
\hline & & 2 & - & - & + & ++ & ++ & + & - \\
\hline & & 3 & - & - & + & ++ & ++ & + & - \\
\hline & & 4 & - & - & + & + & + & + & - \\
\hline & & 5 & - & - & + & ++ & ++ & + & - \\
\hline & \multirow[t]{5}{*}{ IT } & 1 & - & - & + & ++ & ++ & ++ & + \\
\hline & & 2 & - & + & ++ & ++ & ++ & + & - \\
\hline & & 3 & - & - & + & ++ & ++ & + & - \\
\hline & & 4 & - & - & ++ & ++ & ++ & + & + \\
\hline & & 5 & - & - & ++ & ++ & ++ & + & - \\
\hline \multirow[t]{10}{*}{$\mathrm{H} 3 \mathrm{~N} 2$} & \multirow[t]{5}{*}{ IN } & 1 & - & + & ++ & ++ & ++ & + & - \\
\hline & & 2 & - & - & + & ++ & ++ & + & - \\
\hline & & 3 & - & - & + & ++ & ++ & + & - \\
\hline & & 4 & - & - & + & + & + & + & - \\
\hline & & 5 & - & - & + & ++ & ++ & + & - \\
\hline & \multirow[t]{5}{*}{ IT } & 1 & - & - & + & ++ & ++ & ++ & + \\
\hline & & 2 & - & - & ++ & ++ & ++ & + & - \\
\hline & & 3 & - & - & + & ++ & ++ & + & - \\
\hline & & 4 & - & + & ++ & ++ & ++ & + & - \\
\hline & & 5 & - & - & ++ & ++ & ++ & + & + \\
\hline \multirow[t]{10}{*}{ H1N1pdm09 } & \multirow[t]{5}{*}{ IN } & 1 & - & + & ++ & ++ & ++ & + & + \\
\hline & & 2 & - & - & + & ++ & ++ & + & - \\
\hline & & 3 & - & + & + & ++ & ++ & + & - \\
\hline & & 4 & - & - & + & + & + & + & - \\
\hline & & 5 & - & - & + & ++ & ++ & + & - \\
\hline & \multirow[t]{5}{*}{ IT } & 1 & - & - & + & ++ & ++ & ++ & + \\
\hline & & 2 & - & + & ++ & ++ & ++ & + & - \\
\hline & & 3 & - & - & + & ++ & ++ & + & - \\
\hline & & 4 & - & - & ++ & ++ & ++ & + & - \\
\hline & & 5 & - & - & ++ & ++ & ++ & + & - \\
\hline Controls & & $\mathrm{n}=6$ & - & - & - & - & - & - & - \\
\hline
\end{tabular}

Real-time RT-PCR results are given as ++ ( $\mathrm{Ct}$ value $<30$; positive), $+(\mathrm{Ct}$ value $30-35$; weak positive $),-(\mathrm{Ct}$ value $>35$, negative $),-$ negative

the level of TNF- $\alpha$ was observed from 4 to 14 dpi in gilts inoculated with H1N1pdm09 SIV, and only at $7 \mathrm{dpi}$ in other inoculated groups. No significant differences between infected groups were found $(\mathrm{p}>0.05)$.

\section{Acute-phase protein response}

The time course of CRP and Hp concentrations in gilts' serum during the study period is presented in Fig. 9. 
Fig. 6 The mean $( \pm S D)$ concentration of IL-6 in plasma collected from gilts infected intranasally (IN) or intratracheally (IT) with H1N2, H3N2 or H1N1pdm09 swine influenza viruses and in control gilts. *, significant differences between gilts infected with H1N1pdm09 and control gilts; a, significant differences between gilts infected with H3N2 SIV and control gilts; b, significant differences between gilts infected with H1N2 SIV and control gilts; c, significant differences between gilts infected with $\mathrm{H} 3 \mathrm{~N} 2$ or H1N1pdm09 and gilts infected with H1N2 SIV; d, significant differences between infected groups

Fig. 7 The mean $( \pm$ SD $)$ concentration of IL-10 in plasma collected from gilts infected intranasally (IN) or intratracheally (IT) with H1N2, $\mathrm{H} 3 \mathrm{~N} 2$ or H1N1pdm09 swine influenza viruses and in control gilts. *, significant differences between gilts infected with H1N1pdm09 and control gilts; a, significant differences between gilts infected with H3N2 SIV and control gilts; b, significant differences between gilts infected with H1N2 SIV and control gilts; c, significant differences between gilts infected with H1N1pdm09 and gilts infected with H1N2 SIV
IN-inoculation
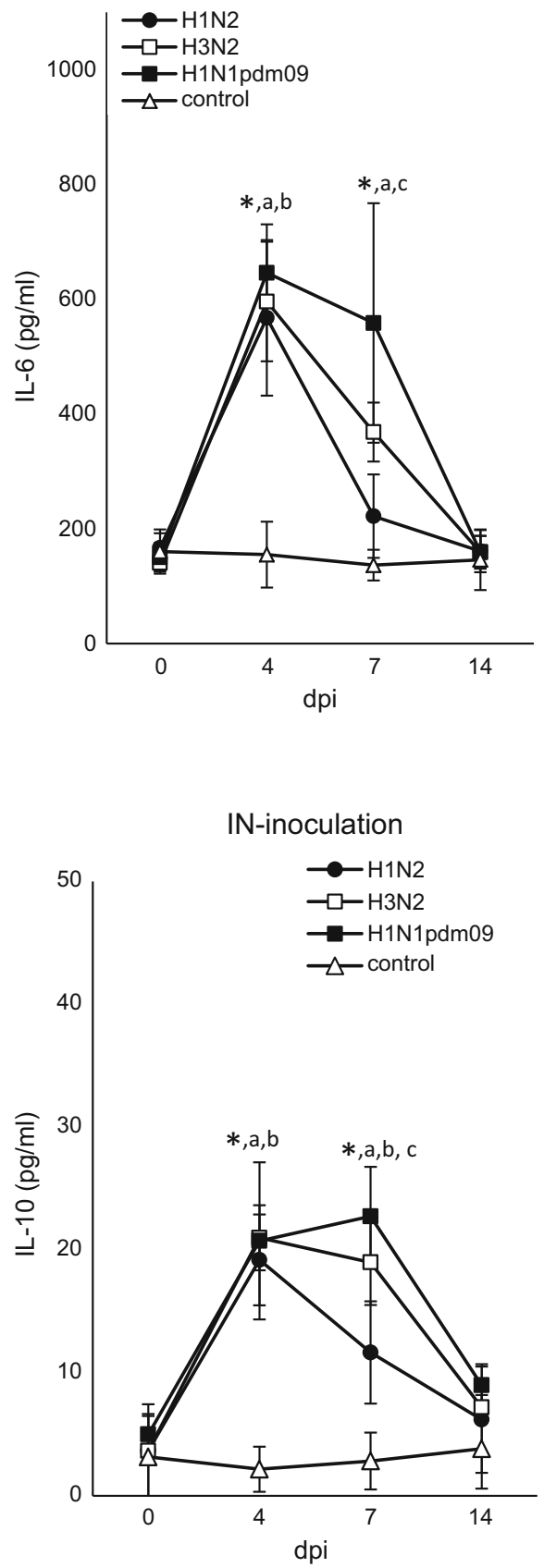

IT-inoculation

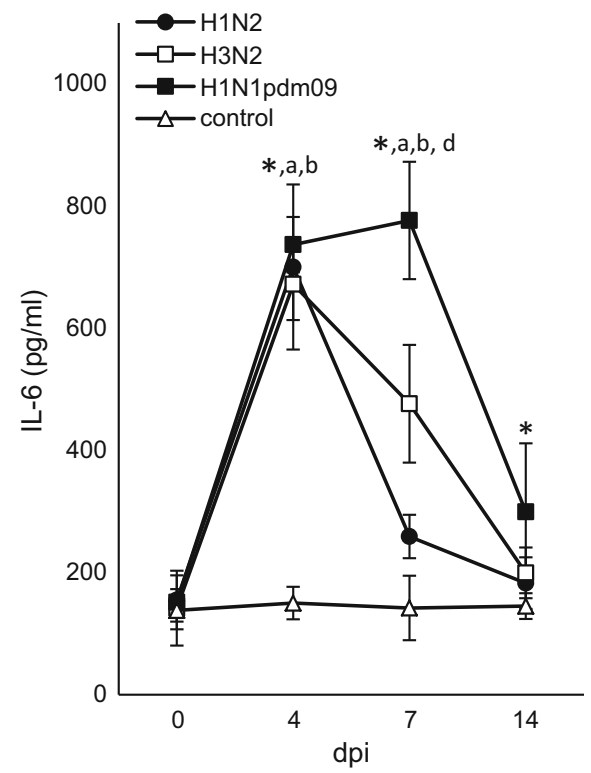

\section{IT-inoculation}

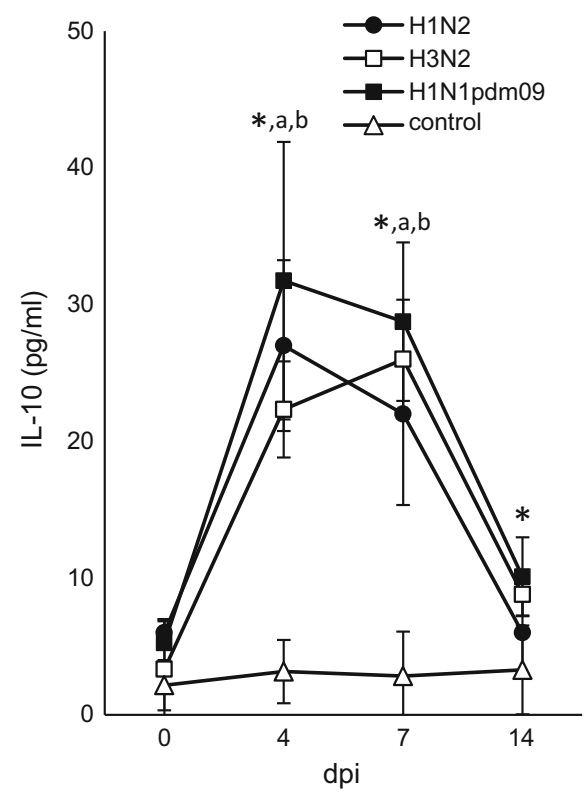

The CRP concentration did not change significantly after IN inoculation with any of the viruses used in this study $(p>0.05)$. Also, no significant differences between the inoculated and control groups were found ( $\mathrm{p} \geq 0.05$ ). In contrast, in gilts inoculated IT with H1N2 and H1N1pdm09 SIV, the concentration of CRP was significantly higher at 4 dpi when compared to control gilts $(\mathrm{p}<0.05)$.

Haptoglobin concentrations increased significantly in IN- and IT-inoculated gilts when compared with control animals $(p<0.05)$. In groups inoculated with H1N2 and
H3N2 SIV, this increase was significant at 4 and $7 \mathrm{dpi}$, while in gilts inoculated with H1N1pdm09, the haptoglobin level was elevated also at $14 \mathrm{dpi}$.

\section{Discussion}

In the present study, the effect of experimental infection with SIV during the third month of gestation on the clinical status and the course of pregnancy was analyzed in naive 
Fig. 8 The mean $( \pm \mathrm{SD})$ concentration of TNF- $\alpha$ in plasma collected from gilts infected intranasally (IN) or intratracheally (IT) with H1N2, H3N2 or H1N1pdm09 swine influenza viruses and in control gilts. *, significant differences between gilts infected with H1N1pdm09 and control gilts; a, significant differences between gilts infected with H3N2 SIV and control gilts; b, significant differences between gilts infected with H1N2 SIV and control gilts; c, significant differences between all infected groups

Fig. 9 The time course of $\mathrm{C}$-reactive protein (CRP) and haptoglobin $(\mathrm{Hp})$ response in gilts inoculated intranasally (IN) or intratracheally (IT) with H1N2, H3N2 or H1N1pdm09 swine influenza viruses and in control gilts. ${ }^{*}$, significant difference compared with control group $(\mathrm{p}<0.05)$
IN-inoculation

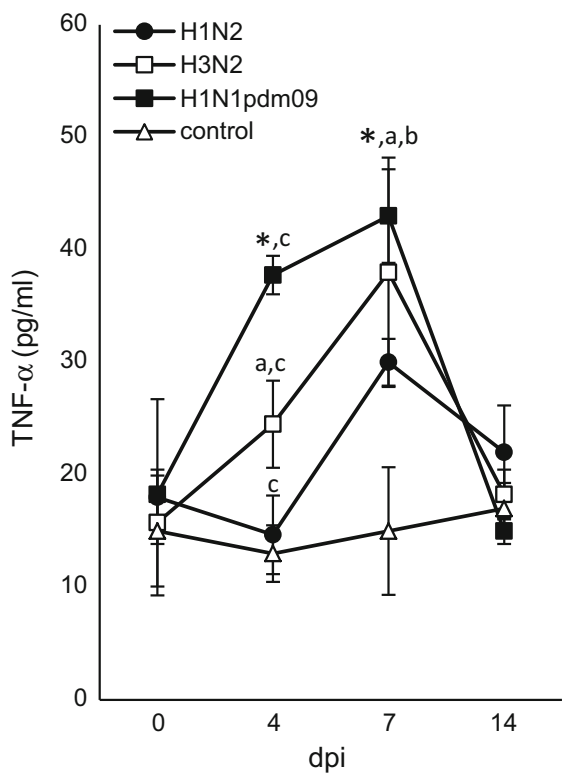

IN inoculation
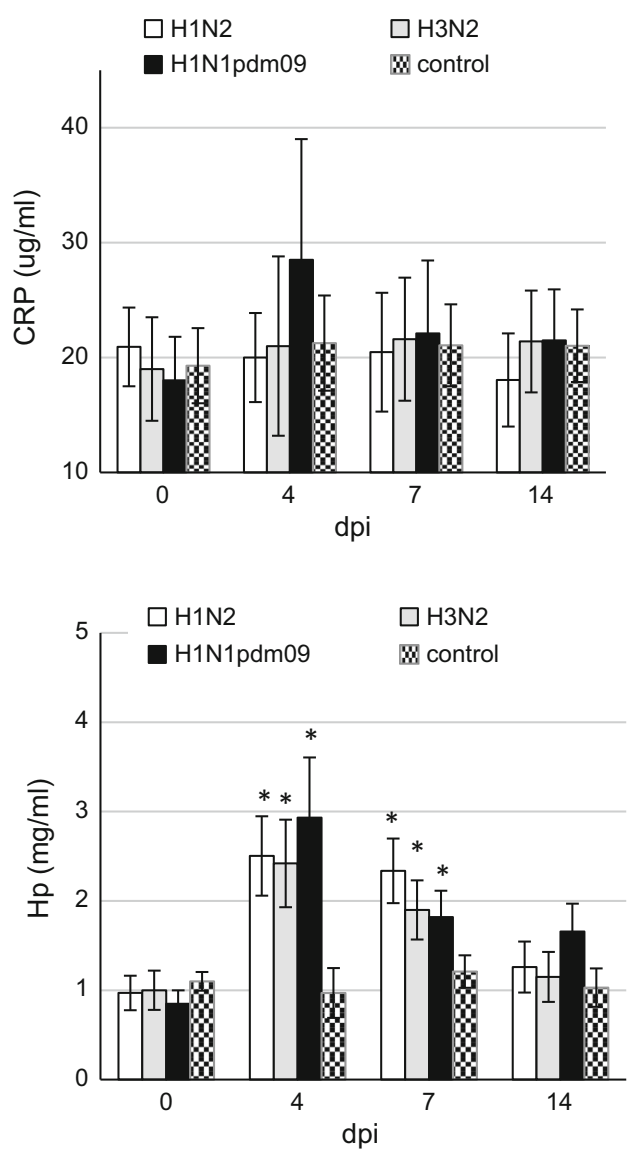

IT-inoculation

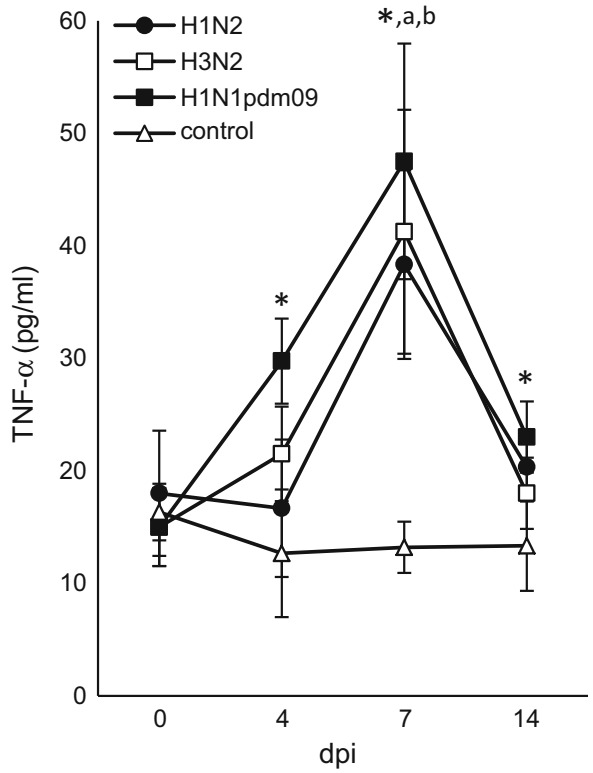

IT inoculation
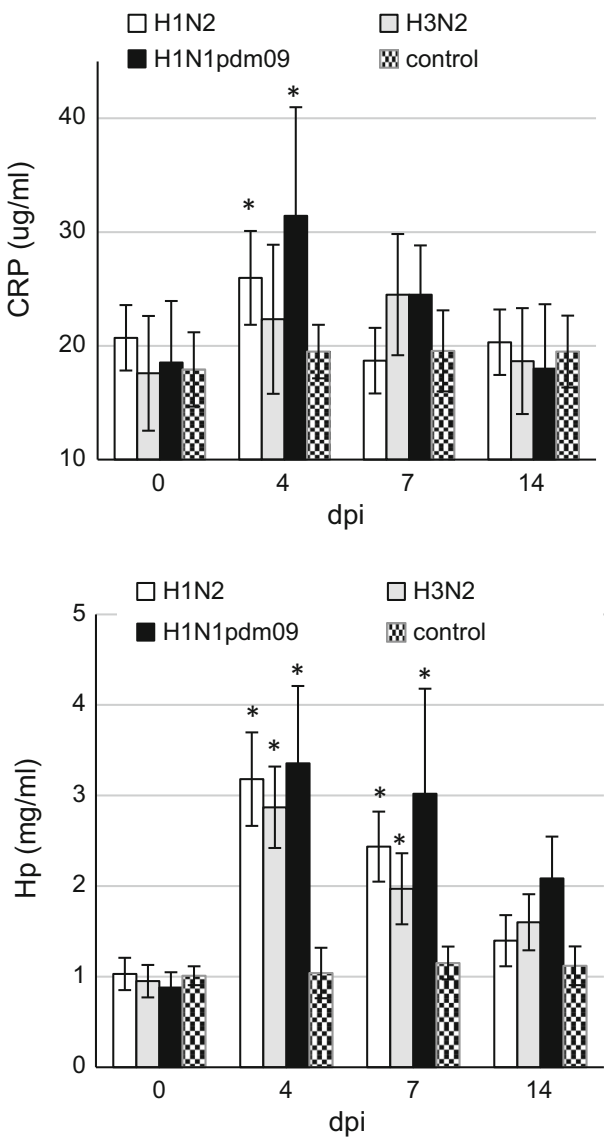
gilts. Reproductive failure in pigs can be caused by several infectious agents. Based on previous studies [4, 5, 10, 16], $\mathrm{SIV}$ is also a possible cause. Influenza-related reproduction disorders may vary depending on the stage of gestation [5, 9]. Affected females can show a range of reproductive problems, including delayed return to estrus, abortions, reduced litter size, and reduced viability of piglets at birth [22]. Abortions and reproductive failure observed in pigs with influenza are often associated with elevated body temperature and acute inflammation; however, transplacental transmission of the virus has been also reported [3$6,14]$. Transplacental transmission of SIV was previously observed in sows and gilts [3-6]. However, the experimental evidence for transplacental transmission of SIV in pigs is inconsistent $[3,6,23,24]$. The most recent results published by Khatri and Chattha [25] indicate that both 2009 pandemic influenza virus and SIV replicate in swine umbilical cord epithelial stem cells (SUCECs). The authors have concluded that influenza virus can infect SUCECs and may transmit influenza virus from mother to fetus through the umbilical cord [25].

In the current study, no reproduction disorders were observed in inoculated and control gilts, and there were no differences between inoculated and control gilts with regard to production and reproductive parameters. It should be noted that, in our study, no typical clinical signs of acute SI were observed in gilts that were inoculated IN. In gilts inoculated IT short-term fever and diminished activity were observed.

No viremia and no evidence for intrauterine transmission of SIV were found in the present experiments. In samples collected from the two weakest piglets, sacrificed just after delivery, and no SIV RNA was detected in the placentas. Colostrum-deprived piglets had no detectable titers of $\mathrm{HI}$ antibodies.

In contrast, Wallace and Elm [9] reported the transplacental transmission of H1N1 SIV in gilts exposed to influenza virus during pregnancy. They also reported that gilts infected during pregnancy delivered a larger number of dead piglets. However, the presence of SIV was confirmed in only 1 out of 10 piglets examined.

In the present study, the concentration of the majority of the investigated cytokines (IL-6, IL-10 and TNF- $\alpha$ ) was significantly higher in plasma of gilts inoculated with SIV than in control gilts. The IL- 4 and IFN- $\gamma$ concentrations in plasma were below the limit of detection in all females in the experiment.

In this study, the concentration of IL-6 in plasma increased quite early (from $4 \mathrm{dpi}$ ) in all infected gilts. Lauder et al. [26] reported that IL-6 has a critical role in coordinating anti-IAV immunity through its ability to limit inflammation, promote protective adaptive immunity, and prevent fatal immunopathology. It seems that early secretion of IL-6 may create an important line of defense against a fatal course of influenza. The results of another study indicate that mice lacking IL-6 are less likely to survive the infection by this means, implying a beneficial effect of IL-6 in controlling the infection [26]. Tumor necrosis factor- $\alpha$ is probably essential for limitation of lung lesions during acute influenza virus infection [27]. In general, the plasma level of TNF- $\alpha$ increased after infection in the current experiments. In gilts infected IN and IT with H1N2 and H3N2 SIV, the level of TNF- $\alpha$ was significantly higher from 4 to $7 \mathrm{dpi}$, while in females inoculated IT with H1N1pdm09 virus, a significantly higher level of TNF- $\alpha$ was observed also at $14 \mathrm{dpi}$. The significant increase in the serum concentration of TNF- $\alpha$ and IL-6 during influenza has also been reported for human patients [28, 29]. A substantial increase was also observed with respect to IL-10 (in general from 4 to $7 \mathrm{dpi}$ ). In gilts that were IT-inoculated with H1N1pdm09, the level of IL-10 was significantly higher from 4 to 14 dpi. IL-10 plays mainly an anti-inflammatory role in the immune system. Its role during influenza virus infection is not fully understood. Sun et al. [30] reported that inhibition of IL-10 signaling during influenza resulted in increased inflammation and decreased survival, while McKinstry et al. [31] observed that inhibition of IL-10 signaling before influenza virus infection enhanced viral clearance and increased survival.

In conclusion, no evidence for transplacental transmission of SIV in pigs was found in the present study. Infection of naïve gilts during the last month of gestation with various subtypes of SIV did not produce significant clinical changes or reproduction disorders. Viremia was also not observed in any of the infected females. On the basis of recent results, we hypothesize that pregnancy failure observed during swine influenza under field conditions is probably related to high fever and pro-inflammatory cytokines rather than a direct effect of the virus on the placenta, embryo or fetus.

Acknowledgments This work was supported by Project N N308 564140, supported by the Polish Ministry of Science and Higher Education.

Open Access This article is distributed under the terms of the Creative Commons Attribution 4.0 International License (http://crea tivecommons.org/licenses/by/4.0/), which permits unrestricted use, distribution, and reproduction in any medium, provided you give appropriate credit to the original author(s) and the source, provide a link to the Creative Commons license, and indicate if changes were made.

\section{References}

1. Givens MD, Marley MS (2008) Infectious causes of embryonic and fetal mortality. Theriogenology 70:270-285

2. Pejsak Z, Markowska-Daniel I, Kowalczyk A, Jabłoński A, Kozaczyński W, Loda M (2005) Reproduction disorders 
connected with swine influenza outbreak in a large farm. Med Weter 61:1154-1159

3. Wesley RD (2004) Exposure of seropositive gilts to swine influenza virus may cause a few stillbirths per litter. Can J Vet Res 68:215-217

4. Grøntvedt CA, Er Ch, Gjerset B, Germundsson A, Framstad T, Brun E, Jørgensen A, Lium B (2011) Clinical impact of infection with pandemic influenza (H1N1) 2009 virus in naïve nucleus and multiplier pig herds in Norway. Influenza Res Treat. doi:10.1155/ 2011/163745

5. Madec F, Kaiser C, Gourreau JM, Martinat-Botte F, Keranflech A (1989) Pathologic consequences of a severe influenza outbreak (swine virus $\mathrm{A} / \mathrm{H} 1 \mathrm{~N} 1$ ) under natural condition in the non-immune sow at the beginning of pregnancy. Comp Immun Microbiol Infect Dis 12:17-27

6. Menšik J, Černý L, Zeman J (1957) Intrauterine transmission of swine influenza. Vet Čas 6:455-465

7. Edwards MJ (2006) Review: hyperthermia and fever during pregnancy. Birth Defects Res A Clin Mol Teratol 76:507-516

8. Moretti ME, Bar-Oz B, Fried S, Koren G (2005) Maternal hyperthermia and the risk for neural tube defects in offspring: systematic review and meta-analysis. Epidemiology 16:216-219

9. Wallace GD, Elm JL (1979) Transplacental transmission and neonatal infection with swine influenza virus (swH1N1) in swine. Am J Vet Res 40:1169-1172

10. Choi YK, Goyal SM, Farnham MW, Joo HS (2002) Phylogenetic analysis of H1N2 isolates of influenza A virus from pigs in the United States. Virus Res 87:173-179

11. Uchide N, Ohyama K, Bessho T, Takeichi M, Toyoda H (2012) Possible roles of proinflammatory and chemoattractive cytokines produced by human fetal membrane cells in the pathology of adverse pregnancy outcomes associated with influenza virus infection. Mediat Inflamm. doi:10.1155/2012/270670

12. Sweet C, Collie MH, Toms GL, Smith H (1997) The pregnant guinea-pig as a model for studying influenza virus infection in utero: infection of fetal tissues in organ culture and in vivo. $\mathrm{Br} \mathbf{J}$ Exp Pathol 58:133-139

13. Rushton DI, Collie MH, Sweet C, Husseini RH, Smith H (1983) The effects of maternal influenza viraemia in late gestation on the conceptus of the pregnant ferret. J Pathol 140:181-191

14. Young GA, Underdahl NR (1950) Swine influenza as a possible factor in suckling pig mortalities. III. Effect of live virus vaccination of the dam against swine influenza on suckling pig mortalities. Cornell Vet 40:24-33

15. Karasin AI, Olsen CW, Anderson GA (2000) Genetic characterization of an $\mathrm{H} 1 \mathrm{~N} 2$ influenza virus isolated from a pig in Indiana. J Clin Microbiol 38:2453-2456

16. Gourreau JM, Kaiser C, Madec F, Labie J, Vannier P, Aymard M, Vigouroux A, Salingardes F (1985) Passage du virus grippal par la voie transplacentaire chez le porc, dans les conditions naturelles. Ann Inst Past Virol 136:55-63

17. Muller E, Knocke KW, Willers H, Jochims R (1981) Occurrence of swine influenza in northern Germany. Prakt Tieraerztl 62:669-672
18. Pomorska-Mól M, Kwit K, Markowska-Daniel I, Kowalski C, Pejsak Z (2014) Local and systemic immune response in pigs during subclinical and clinical swine influenza infection. Res Vet Sci 97:412-421

19. Pomorska-Mól M, Markowska-Daniel I, Kwit K (2012) Immune and acute phase response in pigs experimentally infected with H1N2 swine influenza virus. FEMS Immunol Med Microbiol 66:334-342

20. Pomorska-Mól M, Markowska-Daniel I, Rachubik J (2012) Development of early humoral and cell-mediated immunity in piglets with experimentally induced subclinical swine influenza. Bull Vet Inst Pulawy 56:133-137

21. World Organization for Animal Health (OIE) (2008) Swine influenza. Manual for diagnostic tests and vaccines for terrestrial animals, Paris, pp 1128-1138

22. Morilla A, Yoon KJ, Zimmerman JJ (2008) Trends in viral infection in swine. Wiley, New York

23. Kwit K, Pomorska-Mól M, Markowska-Daniel I (2013) Course of pregnancy in gilts after intranasal infection with the H1N2 subtype of swine influenza virus during the first month of pregnancy. Med Weter 69:641-704

24. Kwit K, Pomorska-Mól M, Markowska-Daniel I (2014) The influence of experimental infection of gilts with swine H1N2 influenza A virus during the second month of gestation on the course of pregnancy, reproduction parameters and clinical status. BMC Vet Res 10:123. doi:10.1186/1746-6148-10-123

25. Khatri M, Chattha KS (2015) Replication of influenza A virus in swine umbilical cord epithelial stem-like cells. Virulence 6:40-49

26. Lauder SN, Jones E, Smart K, Bloom A, Williams AS, Hindle JP, Ondondo B, Taylor PR, Clement M, Fielding C, Godkin AJ, Jones SA, Gallimore AM (2013) Interleukin-6 limits influenzainduced inflammation and protects against fatal lung pathology. Eur J Immunol 43:2613-2625

27. Damjanovic D, Divangahi M, Kugathasan K, Small CL, Zganiacz A, Brown EG, Hogaboam CM, Gauldie J, Xing Z (2011) Negative regulation of lung inflammation and immunopathology by TNF- $\alpha$ during acute influenza infection. Am $J$ Pathol 179:2963-2976

28. Hayden FG, Fritz R, Lobo MC, Alvord W, Strober W, Straus SE (1998) Local and systemic cytokine responses during experimental human influenza A virus infection. Relation to symptom formation and host defense. J Clin Invest 101:643-649

29. Kaiser L, Scott R, Straus SE, Gubareva L, Hayden FG (2001) Symptom pathogenesis during acute influenza: IL- 6 and other cytokine responses. J Med Virol 64:262-268

30. Sun J, Madan R, Karp CL, Braciale JT (2009) Effector T cells control lung inflammation during acute influenza virus infection by producing IL-10. Nat Med 15:277-284

31. McKinstry KK, Strutt TM, Buck A, Curtis JD, Dibble JP, Huston G, Tighe M, Hamada H, Sell S, Dutton RW, Swain SL (2009) IL10 deficiency unleashes an influenza-specific Th17 response and enhances survival against high-dose challenge. J Immunol 182:7353-7363 